INTERNATIONAL JOURNAL OF

MULTIDISCIPLINARY STUDIES ON MANAGEMENT, BUSINESS, AND ECONOMY

\title{
THE ROLE OF INTERNATIONAL COOPERATION IN PROMOTING SUSTAINABLE DEVELOPMENT AND SUPPORTING CONSERVATION AND DEVELOPMENT POLICIES AT THE NATIONAL LEVEL
}

\author{
Sarah El-Sayed ABDEL-RASHID *
}

Faculty of Engineering - Cairo University- Cairo- Egypt.

\begin{abstract}
Efforts to revitalize the global partnership for sustainable development represent one of the main axes for the successful implementation of the 2030 Agenda, as the seventeenth goal of the Sustainable Development Goals called for "strengthening ways to implement and revitalize global partnerships," which represents an important opportunity to broaden the international consensus beyond Defining goals and working to form coordinated networks between countries that facilitate communication processes, encourage confidence-building, and push international cooperation through new paths that go beyond the traditional framework based on aid, and are in line with priorities, local regulations and methodologies appropriate for development, as the preservation of urban heritage in Egypt is one of the most important The areas in which institutions contribute to the deterioration of the urban fabric of areas of historical value, protection of heritage buildings and sites, and the endowment of international bodies with the aim of preserving them. After 2015 and its impact on achieving the goals of regions with special nature and civilized values on the The national level, identifying the funding agencies for the protection of the urban heritage and the development of support methods and participation in these processes and how they are reflected in the development of preservation and development policies for a set of local experiences in this context, through which the strengths and weaknesses of the national level will be determined. And extract a set of conclusions and recommendations related to addressing the gaps and problems that still face the application of principles and policies of international cooperation, and seeks to achieve maximum benefit from them in line with the political, economic and social contexts at the national level and achieve full compatibility between global sustainability requirements and national development priorities.
\end{abstract}

Keywords

INTERNATIONAL COOPERATION, SUSTAINABLE DEVELOPMENT, CONSERVATION, DEVELOPMENT POLICIES.

\section{Introduction}

The term sustainable development appeared for the first time in 1972 in two books, the first is the limits of growth by Donella Meadows, and the second is a blueprint for survival by Edward Goldsmith, and the concept was limited in its inception to summarizing the human relationship towards the environment, where the concept of sustainability emerged as a response to understanding modern development practices and their negative impacts on the natural and social environment. The term "sustainable development" has become the

\footnotetext{
*Corresponding author: info@eng.cu.edu.eg
} 
slogan of alternative development approaches that aim to preserve available resources in light of rapid economic growth.

Many conferences and discussions have been held that sought to define sustainable development in the context of specific topics, defining its dimensions and the main issues that are the focus of attention, the most important of which is the Brundtland Commission's definition that sustainable development is not a process in which a steady state can be reached, but rather a process in which the rates of resource utilization change., The direction of investments, the direction of technological and institutional development in a manner that is consistent and harmonious with the needs of the present and the future, sustainable development does not mean stopping growth, but rather the absence of wasting resources and entails a change in the content of growth to make it less material and energy-intensive, so without growth societies will not be able to provide Its citizens have a decent standard of living and help them work to improve the environment.

The committee also specified that the actual results of sustainability appear through human activities and their environmental impacts in the long term, not just from achieving short-term gains. The philosophical principle that guides sustainable development is to head to the future without ignoring the current living needs of individuals.

The United Nations launched a list of sustainable development goals in July 2015, through which it seeks to bridge the gaps and address the emerging changes that the previous lists could not address, encourage sustainable consumption and production patterns, and protect the natural resource base necessary for economic and social development and manage them as the desired goals of sustainable development and conditions Basic to achieve it.

The seventeenth goal on this list, which calls for strengthening the means of implementation and revitalizing the global partnership for sustainable development, comes as 
one of the basic pillars through which the United Nations seeks to achieve these goals by mobilizing international forces through global, regional, national and local partnerships to develop a future vision based on Common rules, values, goals, and a successful agenda capable of mobilizing supporters and emphasizing the importance of partnerships between all stakeholders concerned with sustainable development at the national and local levels, whether they are governments, the private sector or civil society.

\section{Urban Heritage}

The General Conference of the United Nations Educational, Scientific and Cultural Organization (UNESCO) in its seventeenth session of 1972 in the Convention on the Protection of World Heritage divided the heritage into cultural heritage and natural heritage, and cultural heritage means everything related to monuments and complexes of exceptional universal value from the point of view of history and archaeological sites, while Natural heritage relates to natural features consisting of physical or biological formations, or geological formations composed of habitats of animal or plant species threatened with extinction, or natural sites of exceptional value from the point of view of science or the preservation of wealth and natural beauty.

Urban heritage is considered one of the main outcomes of human development throughout history, and it is a reflection of the human ability to adapt to the surrounding environment, heritage is not limited to language, literature or thought alone, but also includes the material and emotional elements of society with thought, philosophy, religion, science, art and architecture.

The Charter for the Preservation and Development of the Urban Heritage in the Arab Countries, issued by the Arab Organization for Education, Culture and Science, defines urban heritage as all the cities, villages, neighborhoods and buildings that have been constructed by 
humans of archaeological, architectural, urban, economic, historical, scientific, cultural or functional value, and are classified According to the following:

- Heritage buildings, which include buildings of historical, archaeological, artistic, scientific and social importance, including decorations, fixed furniture associated with them, and the environment associated with them, urban heritage areas, and includes cities, villages and neighborhoods of historical, archaeological, artistic, scientific and social importance with all their components of urban fabric, public squares, roads, alleys and services Underscore and others. In urban heritage sites, including buildings associated with a distinct natural environment or man-made. The Arab urban heritage was also defined as every urban heritage that reflects the characteristics of the Arab urban civilization, or represents one of the multiple historical episodes that the Arab nation has passed through and is inherited from generations through the ages.

\section{Preservation and Rehabilitation of Urban Heritage}

Most of the major cities in the world have faced pressure from the requirements of rapid social and economic development over the past few decades. This rapid increase in urban renewal has created heritage problems in these cities. Every new development or redevelopment process tears apart the old fabric and the social and economic character of these towns and cities.

Urban growth aims to improve urban life, and after the emergence of the term "sustainability", planners, developers and policymakers in urban areas began to think about creating and achieving a balance between development and heritage preservation in the coming periods. It also pushed the local community to change aspirations and expectations for the future, and to express concerns about preservation and loss of heritage over time. 


\section{The Concept of Sustainable Conservation}

Preservation is defined as "physical interventions in actual installations to ensure the continuation of their structural integrity." It is also concerned with protecting and protecting historic buildings or of historical value according to advanced scientific methods with the aim of prolonging the life of the heritage building, and combating damage to heritage property, whether natural or human.

The sustainable preservation of heritage is an approach to preserving heritage capabilities without imposing unaffordable costs that may affect the rational balance between conservation and change. It also works to preserve social capital, enhances the sense of belonging to the place and its ownership and generates economic resources.

\section{The Importance of Preserving the Urban Heritage the Preservation of The Urban Heritage Aims at Three Basic Principles, Namely:}

\section{The First}

Achieving the public good: the preservation of the urban heritage contributes to the preservation of cultural and historical properties, as it helps to protect money and the public good, which contributes to improving the quality of life, the quality of life and the sense of belonging.

\section{The Second}

Achieving economic development, as the preservation and protection of urban assets from heritage buildings and sites contributes to enhancing economic development and moving the wheel of growth in the event that they are well and effectively exploited, such as the tourist attraction of urban heritage. 


\section{The Third}

Achieving sustainable development: Urban heritage plays an important role in achieving sustainable development within society by promoting urban development, protecting historical assets, and following the best urban planning methods to protect areas of heritage value.

Development of global and national visions for international partnership and cooperation processes before and after 2015 The Millennium Development Goals issued by the United Nations in 2000 dealt with a major list of 8 goals that seek to eradicate poverty and achieve sustainable development. The eighth goal, "Establishing a Global Partnership for Development", played an important role in mobilizing action and political will towards a basic set of development priorities with the aim of combating poverty in its various forms and manifestations. During the work of the goals from 2000 to 2015, it was able to reinforce the commitment of governments and provide political direction and global mobilization behind A moral purpose is to reduce poverty, while stimulating increased investments in several important areas and mobilizing efforts aimed at promoting development.

According to United Nations reports, remarkable progress has been made in achieving the Millennium Development Goals over the past fifteen years. However, the persistence of gaps in official development assistance has highlighted the need to renew the global partnership for development. The year 2015 was already a year and it was launched. The United Nations has a list of sustainable development goals, which with its 17 goals is a more extensive and comprehensive list compared to the Millennium Development Goals, as it adds to it and to the United Nations Conference on Sustainable Development 2012 (Rio + 20), in order to crystallize a more comprehensive vision aimed at eradicating poverty and creating just and peaceful societies. 
And ensuring economic, environmental and social sustainability, and through Goal 17, the United Nations calls for strengthening ways to implement and revitalize global partnerships for sustainable development by working across a wide range of national contexts and involving many different stakeholders, and being present at multiple levels, whether international, regional, national, or community.

\section{Results}

Urban heritage is an integral part of the cultural, economic and urban structure of any country. Identifying and defining the basic elements of urban heritage and working on establishing original cultural concepts and emphasizing that cities are the "memory of societies", taking into account contemporary requirements in planning and developing cities, is the main factor in achieving sustainable development and preserving this legacy by establishing the concept that what we are building today will be a heritage for future generations.

The international and Arab community has worked to protect the urban heritage according to integrated programs that include restoration, employment, cultural revitalization and economic development projects, considering that the cultural and urban heritage of a country is a legacy that concerns the world All in all, that any loss of this legacy does not stop at the borders of the country that owns or is the incubator of this legacy. Rather, it is considered a loss to human history as a whole. The material, scientific and technological projects to protect and raise the value of the urban heritage, whether classified or not classified within sites World Urban Heritage.

\section{Recommendations}

The most important recommendations concluded by the research paper can be summarized under a set of basic axes, namely: 
Recommendations related to the urban dimension, urban management and limiting the expansion of cities at the expense of traditional areas, and the importance of emphasizing the study of these areas as areas of a special nature, which are rehabilitated taking into account the requirements of originality and integration and the current economic functional dimensions and the development of an appropriate institutional framework to implement a policy Urban preservation, with the ability to implement and improve cooperation between various government agencies and the participating and relevant institutions, and to develop and implement plans for the balance between maintaining the site and the development requirements, while preserving the spaces and urban fabric of existing cities.

Recommendations related to the economic and social dimensions and the development of a proposal for the necessary economic and financial tools - especially with regard to addressing the financial and credit system.

In order to improve rehabilitation work and raise awareness of the private sector about the importance of participating in preserving urban heritage and re-employing it, and making this among its priorities in the field of social responsibility, including supporting local associations to contribute to development, and supporting educational institutions in the field of preserving heritage buildings and re-employing them.

And the development of detailed plans that include training of human resources, starting with the provision of centers that provide heritage awareness programs for the local population, to the technical personnel working in the field of heritage preservation. And to benefit from the urban heritage in the development of the local community through the distribution of the economic return of investments, which contributes to motivating the local population to contribute to the processes of preservation and rehabilitation. Establish monitoring systems based on specific and easy-to-measure measurement indicators. 
Recommendations related to the fields of international cooperation and the sustainability of conservation operations and work on exchanging experiences and successful experiences, establishing strategic partnerships between countries in the field of preserving urban heritage and linking issues of urban heritage preservation with contemporary global issues such as globalization, tourism development and climate change.

\section{References}

1) Convention on the Protection of World Cultural and Natural Heritage, United Nations Educational, Scientific and Cultural Organization, Paris, 1972.

2) The first International Conference on Urban Heritage in Islamic Countries. (2010).

3) Saudi Sport, the first session of the Working Group on sustainable development goals (2013), Tunisia.

4) Sultan, Mohammed Sayed. Issues of urban heritage financing strategic framework for the promotion of heritage conservation and protection (2013).

5) Heritage Forum - The Third National Urban - Medina, Saudi Arabia, The Trust for the Preservation of The Urban Heritage in the Arab Countries and Its Development.

6) Beatley, T., Brower, D. and Schwab, A. (2002). An Introduction to Coastal Zone Management London \& Washington: Island Press. 2nd Edition.

7) Delafons, J. (1997), Politics and Preservation - A Policy History of the Built Heritage 18821996,London: E \& FN Spon .

8) Hassan, F. (2013). Egyptian legislations in relation to the rehabilitation of Historic Cairo. World Heritage Centre, Urban Regeneration for Historic Cairo.

9) Hawas, S (2013). Urban conservation- Regeneration of heritage areas in Egypt- Aga Khan Darb Al-Ahmar Project Model. Cairo Cairo: Aga Khan foundation .

10) United Nations. (2015). Millennium Development Goal 8. Taking Stock of the Global Partnership for Development, MDG Gap Task Force Report 2015, new York. 
11) UNDP. (2009), Going Local to Achieve the Millennium Development Goals, The Netherlands, The Hague. Wheeler, S. (2004). Planning for Sustainability - Routledge Press - Taylor\& Francis Group - London \& New York.

12) Yasin, A. and Wai Ki, P. (2005). Heritage Conservation a tool for Sustainable Urban Regeneration, 41st ISoCaRP Congress.

Received: April 01, 2020

Accepted: June 02, 2020 